\title{
Arrangement Competences of Music Teachers: Readiness to Meet Unexpected
}

\author{
Rytis Urniežius / rytisur@gmail.com \\ Institute of Education, Šiauliai University, Lithuania, LT
}

\begin{abstract}
The article aims to ground the importance of acquiring arrangement skills by music teachers. Arrangement skills are recognized as important however they are often left without proper attention and specification in music teachers training standards and study programmes. Also abilities to arrange music are most often put together with abilities to compose music, yet it can be suggested that the competences of teachers-composers and teachers-arrangers should be distinguished. Arrangement skills appear especially useful when teachers have to collect the repertoire for the performing groups they work with. Important feature of music teachers' practice is that they face a necessity to arrange music for groups of a non-standard instrumentation. It is especially peculiar for countries without a wide network of school wind bands and orchestras. Lack of knowledge about instruments and absence of arrangement skills prevent teachers from exploiting instrumental resources and expanding the repertoire of their instrumental groups. Training music teachers to arrange for non-standard groups determines the necessity to prepare a special arrangement course for students in higher education institutions.
\end{abstract}

\section{Key words}

arrangement, instrumental performing groups, music teacher, teacher training 


\section{Introduction}

The importance of music teachers' competences as arrangers of music intended for their students' ensembles is discussed in the current article. The practice of music teacher-arranger in many aspects is close to the practice of arrangers in other fields of music, however the specificity of music teachers' work determines the exclusiveness of their arrangement activities. The necessity of acquiring arranger's competence becomes obvious in the context of the problems which arise for music teachers at comprehensive or specialized music schools when they encounter the necessity to collect the repertoire for the performing groups they work with. The author of this article endeavoured to raise the problem and to distinguish its most important issues. The comprehensive study of developing arrangement skills for music educators is a task for the future.

The concept of arrangement used in the current article implies a wide range of possibilities to re-score original works for another medium. Creative type of arrangement (when changes of musical material overpass the boundary beyond which music composing sphere begins) is not in the scope of this research ${ }^{1}$. The word arrangement here denotes an adequate transferring of the original music composition to another instrumental embodiment. The difference between the terms arranging and arrangement is inconsiderable (the first term points more to the process and the second to the result of this process), but generally, more broad and comprehensive term arrangement is preferred. In order to avoid confusion of polysemous terms and synonyms, such words as transcription and similar are not used:

“Arranging - often colloquially called 'transcription' or 'adaptation' - actually resembles the process of translation. It is the craft, or art, of rescoring a musical work. The idioms of the original are interpreted in terms of the new language. The medium changes while the spirit and flavour of the music are preserved." 2

The term instrumentation is used in this article to name 1) the distributing musical material to music instruments and 2) instrumental constitution of a performing group. The term orchestration is used occasionally and treated as a constituent of a general concept of arrangement, just applied to large groups such as orchestra or band.

The article deals exclusively with instrumental arrangement, since practice of choral arrangement is a different, specific craft. The subject discussed in this article presumably should be topical for the countries and music education institutions where music teachers are treated first of all as choirmasters meanwhile the instrumental skills of music teachers are restricted with two or three most common instruments (usually piano,

1 On the other hand, the boundaries between the adequate transferring of music material and its changing on a compositional level (i. e. between re-scoring of the work and creative arrangement) are sometimes blurred.

2 ROGERS, Bernard. The Art of Orchestration: Principles of Tone Color in Modern Scoring. Westport, Conn.: Greenwood Press, 1970, p. 174. 
accordion, guitar). Yet none of particular geographical regions is specified: the subject of this article was conceived as a universal and not attached to the peculiarities of any specific country or region.

Technical remedies which help to perform a process of arranging also will not be discussed: the sufficient result of arranger's work can be successfully achieved by using sophisticated computer software as well as with the help of pencil and eraser.

\section{Music teacher as arranger}

The necessity to acquire arrangement skills for the successful work of music teacher appears obvious. Different documents of higher education institutions notice the necessity of arrangement and instrumentation skills for the music teacher. However many learning standards (in Lithuania ${ }^{3}$ as well as in other countries ${ }^{4}$ ) do not distinguish specificity of arrangement but usually insert it into broad list of competences among many other, firstly music theory items. Most documents which deal with music teacher's competences usually do not develop the theme of teacher-arranger. Thus arrangement skills of music teachers are recognized and declared as important, however they are usually left without proper attention and specification. Therefore, the question of implementing these skills in music teachers training practice appears rather vague and problematic. This fact underpins the topicality of the problem discussed in this article.

Annie K. Mitchell grounds the necessity to acquire competences of arrangement and orchestration for a wide range of music specialists and divides them into four categories of occupation:

\footnotetext{
"These vocational skills are essential a) in specialised music industry careers such as composing/arranging, film score writing and songwriting; $b$ ) in school teaching professions; c) in performance and recording where the application of theoretical knowledge to creative practice enhances the arrangements of live and studio performance, and also d) in portfolio careers (typical of today's music industry professional) encompassing these diverse activities." ${ }^{5}$
}

The importance of learning arrangement by music teachers is clearly stated in the second (b) item. It is also important to notice that the author further in her research distinguishes arrangement skills as a separate field of activity thus she does not link up arrangement skills with composing abilities but rather emphasizes the importance of specific arrangement/instrumentation/orchestration skills for the persons engaged in

3 LASAUSKIENĖ, Jolanta. Muzikos mokytojo veikla ir kompetencijos. Mokslo studija. Vilnius: Vilniaus pedagoginio universiteto leidykla, 2010, pp. 46, 54, 57.

4 The Arts Learning Standards. Music by Grade Level, Washington State Learning Standards. 2017. [cit. 2019-0422]. URL: http://www.k12.wa.us/Arts/Standards/2017/MusicStandards.pdf.

5 MITCHELL, Annie K. Teaching arranging to classical and contemporary music students in higher education. Problems in Music Pedagogy, 2017, vol. 16 no. 2, p. $57-74$ (this quotation at p. 58). 
different musical activities (including composing of music). Yet in various other sources devoted to music teachers the arrangement competences are most often put together with music composing abilities. Such linkage can be found in music teaching standards ${ }^{6}$, descriptions and analysis of curricula and teaching programmes ${ }^{7}$ or in some more detail examinations of music teachers identity, creativity, etc. ${ }^{8}$ It should be noted that the meaning of the word arrangement in many sources, especially American, means a creative elaboration of musical material which approaches the music composing level. In case of the latter meaning such placing of arrangement side by side with composing is justified. However, if we use the meaning of this word in a strict academic sense which is defined by Bernard Rogers and presented in the introduction of this article - then it can be suggested that the competences of teachers-composers and teachers-arrangers should be distinguished. Teachers-composers are engaged in creative activities thus providing their students with new musical compositions. These teachers should be regarded as creators of a new music (more or less professional and valuable). Meanwhile teachers-arrangers are capable to adapt already existing variety of musical creations for different performing groups which exist in schools. Teachers-composers, whose composing process likely depends on certain conditions (favourable mood, amount of talent and personal productivity), are able to produce comparatively small amount of output. Skilful arrangers' possibilities to create necessary scores depend almost exclusively on the quantity of time they have. Of course, a lot of teachers combine both types of activities thus making their personalities especially useful for every school. But it can be presumed that not all teachers possess compositional abilities (and teachers who are able to compose artistically valuable "good" music are even less frequent), meanwhile the abilities to arrange music can be considered as more universal, accessible and, after all, they can be acquired by every teacher who possesses a necessary musical background. Thus the craft of arrangement as one of music teachers' competences seems necessary and accessible for practically every music teacher, yet they should be regarded as a separate competence not attached to the ability to compose music.

$6 \quad$ For example, see The Arts Learning Standards. Music by Grade Level, Washington State Learning Standards. 2017. [cit. 2019-04-22]. URL: http://www.k12.wa.us/Arts/Standards/2017/MusicStandards.pdf).

7 KLADDER, Jonathan Ross. Re-envisioning Music Teacher Education: A Comparison of Two Undergraduate Music Education Programs in the USA [online]. 2017, University of South Florida. [cit. 2019-05-02]. URL: https:// scholarcommons.usf.edu/cgi/viewcontent.cgi?article=7916\&context=etd, pp. 91, 128, 224.

8 HARRISON, Scott. Music Teacher Attributes, Identity and Experiences [online]. 2008, Griffith University. [cit. 2019-03-20]. URL: http://hdl.handle.net/10072/23070, pp. 14, 17.

LINDROTH, James Teodor. The Impact of Arranging Music for the Large Ensemble on the Teacher: A Phenomenological Exploration [online]. 2012, University of South Florida. [cit. 2019-05-02]. URL: http//scholarcommons.usf. $\mathrm{edu} / \mathrm{cgi} /$ viewcontent. cgi? article $=5323 \&$ context $=$ etd. 


\title{
Challenges for teachers-arrangers
}

Methods and goals of teaching arrangement are absolutely clear when students are trained to arrange for standard performing groups. Orchestra conductors, bandmasters, composers, musicologists usually take symphony orchestra, wind band, string quartet, etc. as a typical instrumental constitution for study and practical scoring. Meanwhile music teachers (especially in countries without a wide network of school wind bands, orchestras, etc.) face a necessity to arrange music for groups of a non-standard instrumentation. Regrettably, sources of music education research apparently notice but do not analyse the specificity of the work of music teachers-arrangers. At least the author of the current article was not able to find sources dedicated to this subject.

Interestingly, some useful observations concerning different aspects of arrangement for nonstandard groups can be found in a treatise of orchestration which is definitely not a handbook for music teachers. In several editions of The Study of Orchestration Samuel Adler included a chapter on arrangement which contain a sub-chapter on arrangement for atypical instrumental ensembles. Although the treatise by Adler is intended for the broad range of musicians (composers first of all), his ideas presented in this sub-chapter appear especially topical for music teachers. Music teacher in comprehensive or special music school ${ }^{9}$ may face the necessity to arrange a piece of music for all possible combinations of instruments from mixed trio to non-standard wind band or even deficient symphony orchestra. Therefore, many ideas found in Adler's book can be applied in music teacher's practice. According to Adler, the sub-chapter about arranging (Adler uses the term "transcribing") for various instrumental combinations is

\begin{abstract}
"[...] the most important section for many of us who are called upon to transcribe orchestral works for performance by groups, especially school ensembles, which do not always have the full complement of orchestral instruments demanded by a particular score. There is no reason why a great many orchestral, chamber, or piano works should not be adapted to meet the special circumstances in which we may find ourselves. It is very important to expose young people to good music which they can enjoy performing. To transcribe any work, especially a standard orchestral work, to meet the requirements of an often bizarre ensemble may tax our orchestrational skill to the limits. We must not only be aware of the heterogeneous nature of the available instruments, but we need to be conscious of the limited skills that each player brings to the group. These conditions, should, however, only spark our imagination rather than constrain us. For no matter how far-fetched the ensemble, we must be able to include each person present in our transcription." 10
\end{abstract}

$9 \quad$ Although the resources and skills of instrument players in music schools are usually more significant than in comprehensive schools, the importance of arrangement capabilities is equally important for teachers in both institutions.

10 ADLER, Samuel. The Study of Orchestration. Second Edition. New York - London: W/ W. Norton \& Company, 1989, pp. 558-559. This quotation is extracted from the second edition of the book in which some paragraphs of the chapter on arrangement are even more comprehensive than corresponding paragraphs in the third edition. 
The presented quotation highlights several important points which ground the necessity of studying the handicraft of arrangement by music teachers. It is known from experience that various instrumental groups in comprehensive or special music schools (bands, orchestras, folk ensembles, etc.) truly "do not always have the full complement of orchestral instruments demanded by a particular score". This is one of the most specific features of music teacher's work: the structure of instrumental groups they encounter in their work can differ from one another and from typical, standard instrumentations ${ }^{11}$.

Adler also notes that "to meet the requirements of an often bizarre ensemble may tax our orchestrational skill to the limits". This important observation reminds of the high requirements for music teachers as arrangers: although the most sublime knowledge and the most developed skills of arrangement/instrumentation/orchestration are usually attributed to composers, yet music teachers must also know a lot in order to create a score for a set of instruments unusual in professional music performance practice. Teachers often have to work with every instrument which is at hand, thus they are not able to apply the patterns and clichés presented in the textbooks intended for standard groups.

Next, two fragments of Adler's quotation: "we need to be conscious of the limited skills that each player brings to the group" and "we must be able to include each person present in our transcription" are also topical. The specificity of working conditions (seeking to make use of every available instrument) determines that music teachers have to set up a music group by inviting the performers of a different level of accomplishment. This problem is equally topical for teachers who work with both standard and non-standard groups.

Ultimately, the most noble and prospective reason for learning arrangement is the importance "to expose young people to good music which they can enjoy performing". This statement points to a possibility of teachers-arrangers to present artistically valuable creations of the most important authors for their pupils, meanwhile the artistic merit of original works by teachers-composers is often less than average ${ }^{12}$.

11 The shortage of certain instruments in deficient orchestras or bands can be compensated in one or another way. Recommendations on how to cope with deficient instrumentation can be found, for instance, in article DZIUK, Stacy. Choosing and Altering Repertoire for the Small Band. Music Educators Journal, 2018 vol. 104, no. 4, p. 32-38: the author presents a comprehensive survey of possibilities to select artistically valuable repertoire and perform it with a deficient wind band, discusses various possible shortcomings of a band and suggests solutions for compensation of the lacking instruments; options for instruments substitution and some elements of arrangement compositions for non-standard wind bands are also shortly discussed. Filling gaps in band instrumentation can be achieved by attracting students to one or another instrument or convincing players on excessive instruments to shift to other, more seldom, however important instruments: the comprehensive, based on a rich experience article ROGERS, George L. Concert Band Instrumentation: Realities and Remedies. Music Educators Journal, 1991, vol. 77, no. 9, p. 34-39 suggests many solutions of these problems.

12 Of course, pieces selected and arranged by music teachers also cannot be always attributed to music of high artistic value, yet axiological aspects of schoolchildren repertoire are beyond the scope of this article. 


\title{
Teaching of teachers-arrangers
}

Detail examination of standards and curricula from the standpoint of the future teachers-arrangers training in various countries would be important. It could reveal readiness (or, on the contrary, indifference) of higher education institutions to give their students necessary knowledge for their future work. Even a superficial look to some educational standards reveals their attitude towards the importance of such training. For example, the capability of teachers to arrange music for any unexpected non-typical situations and performing groups is mentioned in the National Board for Professional Teaching Standards (USA):

\begin{abstract}
"In response to curricular demands or unusual performance situations, accomplished teachers might arrange music to suit the ability levels and unique instrumentation or voices of school performing groups or classroom situations. When they do so, they demonstrate the creativity, technical facility, and musicality of a skilled arranger. Their arrangements exhibit appropriate instrumentation, voicing, difficulty level, and style while developing and reflecting students' musical growth. When adapting an existing musical setting, they maintain the integrity of the original work." 13
\end{abstract}

It can be only presumed that in countries other than the USA the attitude can be rather different. Some institutions likely have other priorities of teacher education because of different traditions and music education concepts. The possibilities of changing the curricula in favour of arrangement discipline also appear problematic, because the implementation of new subjects in higher education institutions would demand to renounce some earlier established courses and replace them with instrumentation and arrangement disciplines.

But even if arrangement discipline is accepted and incorporated in a curriculum, the process of training students to arrange for non-typical groups might reveal problematic points. It becomes clear that future music teachers-arrangers cannot fully rely on academic instrumentation/orchestration treatises as literature for their studies. It is likely that the rules for standard groups (wind bands, orchestras, woodwind or brass quintets, etc.) described in these books would not always work for non-standard groups. Such sources usually do not include information which could help teacher to deal with unexpected challenges which they meet working with sometimes weird medleys of instruments. Even aforementioned book by Adler which touch upon a subject of arrangement for non-standard instrumentations is more oriented towards the different modifications of standard groups, i. e. the typical instrumentations of orchestra are taken as a basic starting points while non-standard versions of their instrumentation are considered as deviations from the model. The compositions chosen for the repertoire of such nonstandard groups are also usually selected from the literature for standard orchestras

13 Music Standards. First Edition. For teachers of students ages 3-18+. 2001, National Board for Professional Teaching Standards (Preface revised and reformatted in 2015, 2016). [cit. 2019-03-22]. URL: https://www. nbpts.org/wp-content/uploads/ECYA-MUSIC.pdf, p. 23. 
and adapted. Meanwhile music teachers often face the collections of instruments which are not based on any standard orchestra, wind band or chamber group. They should be ready to enlist in their ensembles any instrument which could be useful, including less common professional or even folk instruments. Therefore, aforementioned textbooks and other sources, although in many cases helpful, cannot be universal remedies for music teachers' studies and practices.

These conditions determine the necessity to prepare a special course for music teachers in higher education institutions. Presumably music teacher-arranger should be trained according to the specific programme which cannot be based on any particular standard musical group (e. g. symphony orchestra, wind band) scoring rules but rather on general knowledge about instruments and their application principles. The approximate content of this body of knowledge could be as follows.

- The comprehensive acquaintance with musical instruments should be compulsory for all music teachers who intend to work with instrumental groups in school. The thorough knowledge of instruments for music teachers is highly important and might be even broader than for arrangers who deal with typical, standard media. Knowledge of the technique of, for example, accordion, guitar, recorder, certain folk instruments, etc. enables music teachers to include them into performing group and prevents arranger from creating passages inappropriate for instrument's technique in their scores.

- A special attention in arrangement course should be paid to the peculiarities of musical texture. An ability to create musical texture is no less important than instrumentation knowledge. Students must know a specificity of texture applied in music for band, orchestra, other instrumental groups and individual instruments. Having in possession a non-standard instrumental group firstly raises a question of the specificity of texture which could be created not only in accordance with the original, but also regarding the collection of instruments, their capabilities, tessituras and other features. The distribution of instrumental timbres can be varying and miscellaneous meanwhile the rules of creating texture are more rigid and demand profound knowledge as well as intuition. As a result of a successful handling both texture and timbres, music teachers would be able to reach a balance between sounding groups and individual instruments in their arrangements.

- Textbooks for standard instrumental groups contain rather strict regulations of how to apply one or another instrument in specific textural conditions (Rimsky-Korsakov, Piston, Adler, etc.), but they cannot prepare arrangers for every possible situation. Nevertheless, the knowledge of classical orchestration rules is a helpful tool for arranger who can creatively adapt the main principles of these rules to the particular (although sometimes very atypical) situations by combining instrumental timbres, assigning instruments to the layers of texture, creating individual parts. 
In general, it can be stated that: 1) the lack of knowledge about instruments and 2) absence of skills of their application (i. e. arrangement skills) hinder music teachers from employing the instrumental resources which can be at hand in their schools. Incompetence to arrange music prevents music teachers from expanding the repertoire of their instrumental groups. Being unafraid of musical instruments of different families and transposing inconveniences, knowing the ways of how to write idiomatically for each instrument and how to combine them in a cohesive musical fabric would significantly expand the possibility of music teachers to exploit resources of musical expression and to present a wider range of valuable music to their pupils.

\section{Bibliography}

The Arts Learning Standards. Music by Grade Level, Washington State Learning Standards. 2017. [cit. 2019-04-22]. URL: http://www.k12.wa.us/Arts/Standards/2017/MusicStandards.pdf.

Music Standards. First Edition. For teachers of students ages 3-18+. 2001, National Board for Professional Teaching Standards (Preface revised and reformatted in 2015, 2016). [cit. 2019-03-22]. URL: https://www.nbpts.org/wp-content/uploads/ECYA-MUSIC.pdf.

ADLER, Samuel. The Study of Orchestration. Second Edition. New York - London: W/ W. Norton \& Company, 1989.

DZIUK, Stacy. Choosing and Altering Repertoire for the Small Band. Music Educators Journal, 2018 vol. 104 , no. 4, p. 32-38.

HARRISON, Scott. Music Teacher Attributes, Identity and Experiences [online]. 2008, Griffith University. [cit. 2019-03-20]. URL: http://hdl.handle.net/10072/23070.

KLADDER, Jonathan Ross. Re-envisioning Music Teacher Education: A Comparison of Two Undergraduate Music Education Programs in the USA [online]. 2017, University of South Florida. [cit. 201905-02]. URL: https://scholarcommons.usf.edu/cgi/viewcontent.cgi?article=7916\&context=etd.

LASAUSKIENĖ, Jolanta. Muzikos mokytojo veikla ir kompetencijos. Mokslo studija. Vilnius: Vilniaus pedagoginio universiteto leidykla, 2010.

LINDROTH, James Teodor. The Impact of Arranging Music for the Large Ensemble on the Teacher: A Phenomenological Exploration [online]. 2012, University of South Florida. [cit. 2019-05-02]. URL: http//scholarcommons.usf.edu/ cgi/viewcontent.cgi?article=5323\&context=etd.

MITCHELL, Annie K. Teaching arranging to classical and contemporary music students in higher education. Problems in Music Pedagogy, 2017, vol. 16 no. 2, p. 57-74.

ROGERS, Bernard. The Art of Orchestration: Principles of Tone Color in Modern Scoring. Westport, Conn.: Greenwood Press, 1970.

ROGERS, George L. Concert Band Instrumentation: Realities and Remedies. Music Educators Journal, 1991, vol. 77, no. 9, p. 34-39. 
